Kansas State University Libraries

New Prairie Press

\title{
NONLINEAR MODELING OF pH DECLINE IN BEEF CARCASSES
}

\author{
James R. Schwenke
}

Curtis L. Kastner

Follow this and additional works at: https://newprairiepress.org/agstatconference

Part of the Agriculture Commons, and the Applied Statistics Commons

\section{(c) $($ ) $\ominus$}

This work is licensed under a Creative Commons Attribution-Noncommercial-No Derivative Works 4.0 License.

\section{Recommended Citation}

Schwenke, James R. and Kastner, Curtis L. (1989). "NONLINEAR MODELING OF pH DECLINE IN BEEF CARCASSES," Conference on Applied Statistics in Agriculture. https://doi.org/10.4148/2475-7772.1448

This is brought to you for free and open access by the Conferences at New Prairie Press. It has been accepted for inclusion in Conference on Applied Statistics in Agriculture by an authorized administrator of New Prairie Press. For more information, please contact cads@k-state.edu. 
NONLINEAR MODELING OF PH DECLINE IN BEEF CARCASSES

\author{
James R. Schwenke \\ Department of Statistics \\ Curtis L. Kastner \\ Department of Animal Sciences and Industry \\ Kansas State University \\ Manhattan, Kansas 66506
}

Abstract

Electrical stimulation speeds the rate of $\mathrm{pH}$ decline in beef muscle. A study was conducted to evaluate an electrical stimulation (ES) method. for beef sides and its effect on $\mathrm{pH}$ decline compared to non-stimulated control counterparts using nonlinear modeling. The $\mathrm{pH}$ of each carcass in the study was measured at selected times over a 24-hour time period postmortem. A statistical methodology is described for comparing two treatments based on the mean $\mathrm{pH}$ decline over time. The repeated measures structure of the data is incorporated into the statistical procedure. A nonlinear exponential decay model is used to characterize the mean $\mathrm{pH}$ decline. Various comparisons of the mean response to treatment are made based on the nonlinear model.

KEYWORDS: Linear models; Non-linear models; Repeated measures analysis

1. Introduction

A study was conducted to compare electrical stimulation (ES)

processing method of beef carcasses to non-stimulation processing method, as a control, on the basis of relative rate of $\mathrm{pH}$ decline. Electrical stimulation is the process of electrically shocking carcasses or sides postmortem to enhance product quality, i.e., tenderness, color, or grade. The experimental design was a completely randomized design with sides of 43 beef carcasses being randomly assigned to either the control or ES treatment group. The carcass information was lost for the statistical analysis, and thus, the sides were analyzed as independent experimental units. The $\mathrm{pH}$ readings were recorded in the longissimus muscle at 1,2 , $4,6,8$, and 24 hours postmortem. Sides were electrically stimulated at 1 hour postmortem, just prior to the first $\mathrm{pH}$ recording using the iodoacetate technique. The observed $\mathrm{pH}$ response data for 10 randomly selected sides are displayed in Figures $1 a$ and $1 b$, for the control and ES treatment groups, respectively. Figures $2 a$ and $2 b$ are plots of these same data, with the observations connected by lines indicating the individual sides for the control and ES treatment groups, respectively.

To better evaluate the relative effectiveness of ES compared to the control, the mean $\mathrm{pH}$ decline in beef muscle for each treatment group was modeled as a function of time. Traditionally, to incorporate the repeated measures structure of the data, a common response model is fit to each individual subject's data. The estimated parameters then are analyzed in an analysis of variance and conclusions of the effectiveness of treatment are based on the mean of the estimated parameters. In the linear model case, this is a relatively easy process. Here, $\mathrm{pH}$ decline is more appropriately modeled as a nonlinear function in time, with $\mathrm{pH}$ declining to an asymptotic value. As can be seen in Figures $2 a$ and $2 b$, a 
by-subject approach to analyzing these data would not be recommended, because it is apparent that the data observed for an individual side are relatively poor representations of a common response function. It would be difficult to estimate the parameters of a common nonlinear model for each individual side using iterative, nonlinear techniques. A different methodology must be employed to obtain adequate estimates of the mean $\mathrm{pH}$ decline and still maintain the repeated measures structure of the data in the hypothesis testing process.

A methodology based on modeling the observed mean response over time is presented in the following sections. The repeated measures structure of the data is incorporated into the hypothesis testing process by obtaining a model-free estimate of the variance-covariance structure of the data. The distribution of the estimated model parameters is then written as a function of recording times and the variance-covariance of the observed data.

\section{Motivation}

To motivate the proposed methodology, the linear model case is considered in this section. Let $\underline{y}_{i}=\underline{X} \underline{\beta}+\underline{\epsilon}_{i}$ define the linear model describing the $i^{\text {th }}$ subject's data across $t$ sampling times, where $y_{i}$ is the txl vector of responses, $X$ is the txp matrix of independent variables, $\underline{\beta}$ is the pxl vector of model parameters, and $\underline{\epsilon}_{i}$ is the txl random error vector, $i=1,2, \ldots, n$. Here, $i t$ is assumed that a common sampling scheme, corresponding to $X$, is used for all subjects. For testing purposes, it is assumed that $\underline{\epsilon}_{i}$ is distributed as $N(\underline{0}, \underline{V})$, where $\underline{0}$ is the txl vector of zeros, and $\underline{V}$ is the txt variance-covariance matrix involving both between subject and within subject variance parameters. The exact structure of $\underline{V}$ need not be specified, but it is assumed that

this structure is common for all subjects in a particular treatment group. The traditional analysis would be to obtain estimates of $\underline{\beta}$ for each subject. The least squares estimate of $\beta$ computed from the observed data for subject $i$ is $\hat{\beta}_{-i}=\left(\underline{X}^{\prime} \underline{X}^{-1} \underline{X}^{\prime} \underline{Y}_{i}\right.$ (Draper and Smith, 1981). Because a common $\underline{V}$ for all subjects is assumed, the $\hat{\beta}_{-}$for all subjects have a common variance-covariance structure. The average of the estimated model parameters across subjects is the least squares estimate of $\beta, \hat{\beta}=$ $\mathrm{n} \wedge$ $\left(\sum_{i=1} \beta_{i}\right) / n$. Traditional analyses, such as analysis of variance procedures or confidence interval computations, can be conducted using the $\hat{\beta}_{-i}$ as the observed response data.

As an alternative strategy, an analysis is presented here based on the across-subject mean at each sampling time point. The overall objective of the analysis is to characterize the mean response to treatment over time. Let $\underline{Y}$ be the nxt observed data matrix, where 
subjects define the rows and sampling times define the columns. Let $\bar{y}=$ $j^{\prime} Y / n$ be the txl vector of across-subject means at each sampling time point, where $j$ is an $n \times 1$ vector of ones. Compute the least squares estimate of $\beta$ from the observed across-subject means, without regard to the sampling distribution of $\bar{y}$, as $\hat{\beta}=\left(X^{\prime} \underline{X}\right)^{-1} \underline{X}^{\prime} \bar{y}$. Now, the sampling distribution of $\overline{\mathrm{y}}$ is $\mathrm{N}\left(\mathrm{X} \underline{\beta}, \underline{\mathrm{V}}^{*}\right)$, where $\mathrm{V}^{*}$ is the txt variance-covariance matrix involving both between-subject and within-subject variance parameters. With $n$ subjects and no missing data, $\underline{V}^{*}=V / n$. The sampling

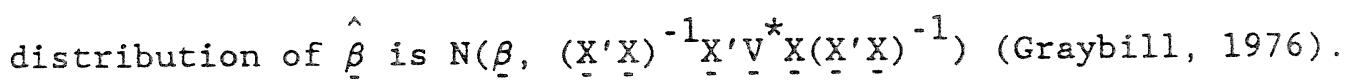

Employing standard multivariate techniques, obtain an estimate of the variance-covariance matrix of the observed data for each treatment group. Let $\hat{V}=\underline{Y}^{\prime}\left(I_{-n}-J_{n} / n\right) Y /(n-1)$ be the estimate of $\underline{V}$, where $I_{n}$ is the $n \times n$ identity matrix and $J_{-n}$ is the nxn matrix of ones (Morrison, 1976). The estimated variance-covariance matrix of the sampling means is then $\hat{\mathrm{V}}^{*}=$ $\hat{\mathrm{V}} / \mathrm{n}$. The sampling distribution of $(n-1) \hat{\mathrm{V}}^{*}$ is Wishart, $\mathrm{w}_{t}\left(\mathrm{n}-1, \mathrm{~V}^{*}\right)$. It follows that for any nonzero vector $g$, $(n-1) g^{\prime} \hat{V}^{*} g / g^{\prime} \underline{V}^{*} g$ is distributed chi-squared with $n-1$ degrees of freedom (Timm, 1975). Consider the null hypothesis $H_{0}: \underline{h}^{\prime} \underline{B}=\underline{h}_{0}$ versus $H_{1}: \underline{h}^{\prime} \underline{\beta} \neq \underline{h}_{0}$. The test statistic for testing $H_{0}$ in favor of $H_{1}$ would be $T=\left(\underline{h}^{\prime} \hat{\beta}-\underline{h}_{0}\right)$ / $\left[\underline{h}^{\prime}\left(\underline{X}^{\prime} \underline{X}^{\prime}\right)^{-1} \underline{X}^{\prime} \underline{V}^{*} X\left(\underline{X}^{\prime} X \underline{X}\right)^{-1} \underline{h}\right]^{\frac{1}{2}}$. Given $H_{0}$ to be true and letting $g=$ $\underline{h}^{\prime}\left(\underline{X}^{\prime} X\right)^{-1} \underline{X}^{\prime}, T$ follows a t-distribution with $\mathrm{n}-1$ degrees of freedom.

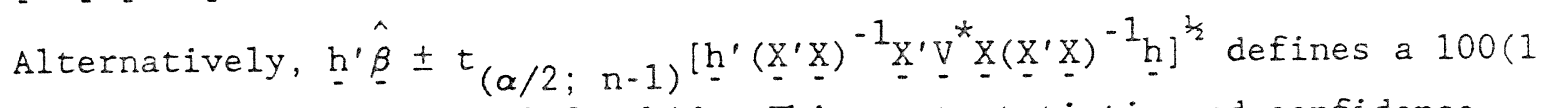
- $\alpha)$ \& confidence interval for $\underline{h}^{\prime} \underline{\beta}$. This test statistic and confidence interval are equivalent to those obtained from the by-subject analysis discussed at the beginning of this section, employing traditional techniques using each subject's $\hat{\beta}_{-i}$ as the observed response data.

An example demonstrating the usefulness of this equivalence is discussed in the next section. A pragmatic extension of the analysis of mean responses to the case of nonlinear models is presented.

3. Modeling $\mathrm{pH}$ Declines

Returning to the example discussed in the Introduction, Figures $2 a$ and $2 \mathrm{~b}$ are plots of the $\mathrm{pH}$ decline of randomly selected sides of beef under control and ES-treated conditions. It is evident that, for each treatment group, the data taken as a whole suggest a common response function over time. A nonlinear decay function has traditionally been useful in characterizing such data. Figures $3 a$ and $3 b$ are plots of the 
entire observed data set, with a line connecting the observed mean at each sampling time. The sampling means demonstrate a well behaved nonlinear trend. Relying on the well-known asymptotic theory of nonlinear models, the means analysis discussed in section 2 is extended to nonlinear models and used to compare the difference in mean response to treatment.

Define the nonlinear decay function as $\mathrm{pH}=\beta_{0}-\beta_{1}\left(1-\exp \left(-\beta_{2}\right.\right.$ time)), where $\beta_{0}$ is the $y$-intercept, $\beta_{0}-\beta_{1}$ is the asymptotic minimum value of the $\mathrm{pH}$ decline, and $\beta_{2}$ is the rate parameter. Note that $\beta_{0}$ is not an informative parameter for this particular data set, because a rapid change in $\mathrm{pH}$ occurs after slaughter and prior to treatment. No data were observed during this time period, but the first observation was at 1 hour postmortem and immediately following treatment. The nonlinear model defined above is used to characterize the $\mathrm{pH}$ decline after 1 hour postmortem.

The across-subject means for each treatment group are given in Table 1. The nonlinear decay function is fit, using standard nonlinear estimation techniques, to the sampling time means. To estimate the model parameters, the response function is fit directly to the sampling time means, without regard to variance-covariance structure among the sampling time means. Figures $4 \mathrm{a}$ and $4 \mathrm{~b}$ are plots of the sampling time means and the estimated response models.

The variance-covariance structure of the sampling time means is incorporated into the hypothesis testing process. The sample variancecovariance matrix of the sampling time means for each treatment is given in Table 2. (An i subscript will be used to denote the two treatments, i $=1$ for control and $i=2$ for $E S$, for the remainder of this paper.) A chi-squared test of $\mathrm{H}_{0}: \mathrm{V}_{-1}=\mathrm{V}_{-2}$ versus $\mathrm{H}_{1}: \mathrm{V}_{-1} \neq \mathrm{V}_{2}$ results in a chisquared test statistic of 126.7 with 21 degrees of freedom (Morrison, 1976). This gives a p-value of less than 0.0001 , and the null hypothesis is rejected.

The asymptotic sampling distribution of $\hat{\beta}_{-i}$ is $N\left(\underline{\beta}_{i},\left(\underline{Z}_{-i}^{\prime} \underline{Z}_{i}\right)^{-1}\right.$ $\left.z_{i}^{\prime} V^{*} Z_{i}\left(z_{i}^{\prime} z_{i}\right)^{-1}\right)$, where $z_{i}$ is the nxp matrix of partial derivatives with respect to the parameters of the response function for treatment i (Jennrich, 1969). The estimated model parameters for each treatment group are given in Table 3 with asymptotic 958 confidence intervals, using $\hat{V}_{-i}^{*}$ to estimate $V_{i}^{*}$. Figure 5 is a plot of the estimated response functions for the control and ES treatments. To test hypotheses of the form $H_{0}: \underline{h}^{\prime} \underline{\beta}_{1}=\underline{h}^{\prime} \underline{\beta}_{-2}$ versus $\mathrm{H}_{1}: \underline{h}^{\prime} \underline{\beta}_{-1} \neq \underline{h}^{\prime} \underline{\beta}_{-2}$, Welch's adjustment to the degrees of freedom is used to accommodate the unequal variance-covariance matrices (Winer, 1971). For this application, Welch's adjusted degrees of freedom is df ${ }^{*}=\left[\left[\operatorname{Var}\left(\underline{h}^{\prime} \hat{\beta}_{1}\right)+\operatorname{Var}\left(\underline{h}^{\prime} \hat{\beta}_{-}\right)\right]^{2} /\left[\left(\operatorname{Var}\left(\underline{h}^{\prime} \hat{\beta}_{-1}\right)\right]^{2} /\left(\mathrm{n}_{1}-1\right)\right)+\right.$ $\left.\left.\left(\left[\operatorname{Var}\left(h^{\prime} \hat{\beta}_{-}\right)\right]^{2} /\left(\mathrm{n}_{2}-1\right)\right)\right]\right\}-2$. The test statistic for testing $\mathrm{H}_{0}$ versus $\mathrm{H}_{1}$ would be $T=\left[\underline{h}^{\prime} \hat{\beta}_{-1}+\underline{h}^{\prime} \hat{\beta}_{-2}\right] /\left[\underline{h}^{\prime} \hat{\underline{W}}_{-1} \underline{h}+\underline{h}^{\prime} \hat{\underline{W}}_{-} \underline{h}\right]^{3 / 2}$, where $\hat{\mathrm{W}}_{-i}$ is the sample 
variance-covariance matrix of $\hat{\beta}_{i}$. The asymptotic distribution of $T$ is t $\left(\mathrm{df}^{*}\right)$, where $\mathrm{df}^{*}$ is Welch's adjusted degrees of freedom. Results of comparison of the model parameters for the two treatments, using Welch's adjusted degrees of freedom, are given in Table 4. Recall that for this example, $\beta_{0}$, and thus $\beta_{1}$, are not particularly meaningful because of when the data were collected, but that $\beta_{0}-\beta_{1}$ is. The conclusions drawn here are that the two treatments have similar terminal $\mathrm{pH}$ levels but that the rate at which these levels are achieved differ, with the ES treatment having a significantly faster decline.

The difference in the expected response to treatment also can be compared by considering the estimated difference in $\mathrm{pH}$ for the treatments across time directly (Hinds and Miliken, 1987). Let $\hat{y}_{1}(t)-\hat{y}_{2}(t)$ define the point estimate of the difference in expected $\mathrm{pH}_{\lambda}$ response at time $t$. The estimated variance of this contrast is $\operatorname{Var}\left(y_{1}(t)-y_{2}(t)\right)=$ $\hat{z^{\prime}} \hat{W z}$, where $\hat{z}$ is the pxl vector of partial derivatives with respect to $\hat{y}_{1}(t)-\hat{y}_{2}(t)$ evaluated at $\hat{\beta}_{-1}$ and $\hat{\beta}_{-2}$, respectively, and $\hat{W}$ is the block diagonal sample variance-covariance matrix of $\left[\hat{\beta}_{1}^{\prime}, \hat{\beta}_{2}^{\prime}\right]$. An asymptotic $100(1-\alpha)$ \& confidence interval for the difference in treatment response at time $t$ is $\left(\hat{y}_{1}(t)-\hat{y}_{2}(t)\right) \pm t\left(\alpha / 2 ; d f^{*}\right)\left(\hat{z}^{\prime} \hat{w z}\right)^{3 / 2}$, where $d f^{*}$ is again Welch's adjusted degrees of freedom.

For this example, the choice of the nonlinear decay model was based on the adequacy of the model to describe the mean of the observed data and not entirely based on theoretical considerations of the biological mechanics of $\mathrm{pH}$ declines in beef carcasses after slaughter. The mathematical relationship between two nonlinear decay curves of the form used here is that, in the terminal time period, they will either reach the same asymptotic $\mathrm{pH}$ level at time infinity, cross at a particular time, or never achieve equal $\mathrm{pH}$ levels. More realistically, given the result of no significant difference being detected in the asymptotic pH level (Table 4), the two treatments probably reach their respective terminal mean $\mathrm{pH}$ levels at some time and maintain this level. A pragmatic solution for estimating the time at which the two treatments achieve equal mean $\mathrm{pH}$ levels would be to construct a $100(1-\alpha)$ \& confidence bound on the difference in mean $\mathrm{pH}$ as described above. A point estimate of the time for the two treatments to achieve equal mean $\mathrm{pH}$ levels then would be the time at which the lower confidence bound on the difference in mean $\mathrm{pH}$ equals zero. Figure 6 is a plot of the difference in mean $\mathrm{pH}$ of the two treatments, with a 958 lower confidence bound on the difference. A point estimate of the time at which nonsignificantly different mean $\mathrm{pH}$ levels are achieved would be 13.91 hours postmortem.

A final approach to compare the mean response of the two treatments is through calibration techniques. A pH of 6.0 is used to indicate when muscle will no longer be susceptible to cold-induced toughening. Thus, a comparison of the mean time when $\mathrm{pH} 6.0$ is achieved would be a comparison of response to treatment. An asymptotic $100(1-\alpha)$ z confidence interval 
for the time to achieve $\mathrm{pH} 6.0$ can be defined by the set of values of $t$ that satisfy $\left|\hat{y}_{i}(t)-6.0\right| /\left(\hat{z}^{\prime} \hat{W}_{i} \hat{z}\right)^{3 / 2} \leq t_{(\alpha / 2}$; dif $)$, where $\hat{W}_{i}$ is the sample variance-covariance matrix of $\hat{\beta}_{-i}$ and $d f$ is the associated degrees of freedom (Schwenke and Milliken, submitted for publication). Table 5 gives the calibrated point estimates and 958 confidence intervals for the time to achieve $\mathrm{pH} 6.0$ for each treatment. To compare the time to achieve $\mathrm{pH} 6.0$ between treatments, consider the null hypothesis $\mathrm{H}_{0}$ :

$t_{1}(6.0)=t_{2}(6.0)$ versus $H_{1}: t_{1}(6.0) t_{2}(6.0)$, where $t_{i}(6.0)$ is the mean time for treatment $i$ to achieve $\mathrm{pH} 6.0$. This is a comparison of times, that is, the models characterizing the mean $\mathrm{pH}$ decay of each treatment may be different, yet achieve a specified $\mathrm{pH}$ at the same time. Let $t_{0}$ be the time to achieve $\mathrm{pH} 6.0$, given that the null hypothesis is true. An estimate of $t_{0}$ would be the value of $t$ that minimizes $\left.\left[\hat{y}_{1}(t)-6.0\right)^{2}\right)$ $\left.\left(\hat{z}_{-1} \hat{W}_{1} \hat{z}_{-1}\right)\right]+\left[\left(\hat{y}_{2}(t)-6.0\right)^{2} /\left(\hat{z}_{-2} \hat{W}_{-2} \hat{z}_{-2}\right)\right]$. The test statistic for testing $H_{0}$ versus $H_{1}$ would be $T=\left[\hat{y}_{1}\left(\hat{t}_{0}\right)-\hat{y}_{2}\left(\hat{t}_{0}\right)\right] /\left[\hat{z}_{-1}^{\prime} \hat{W}_{1} \hat{z}_{1}+\hat{z}_{-2} \hat{W}_{2}\right.$ $\left.\hat{z}_{2}\right]^{\frac{1}{2}}$, where $\hat{z}_{i}$ is the pxi vector of partial derivatives with respect to $\hat{y}_{i}\left(\hat{t}_{0}\right)$ evaluated at $\hat{\beta}_{-i}$ at time $\hat{t}_{0}$, and $\hat{W}_{-i}$ is the sample variancecovariance matrix of $\hat{\beta}_{-i}$. The asymptotic distribution of $T$ is $t$ (df*), where $\mathrm{df}^{*}$ is Welch's adjusted degrees of freedom. The test comparing the time to achieve $\mathrm{pH} 6.0$ for each treatment is summarized in Table 6. Based on this comparison, it is concluded that the treatments achieve mean $\mathrm{pH} 6.0$ at significantly different times, with the ES treatment achieving $\mathrm{pH} 6.0$ sooner.

4. Summary

A methodology is presented that enables an analysis, in a regression context, of repeated measures data based on the across-subject means at each sampling time. In the linear model case, with no missing data, this analysis is equivalent to a by-subject analysis in which a common response model is fit to each subject's data. The benefit of the means approach, in the linear model case, is that only one estimation process is needed to characterize each treatment, instead of one process for each subject. The variance-covariance matrix of the data is estimated through standard multivariate techniques, independent of the model used to characterize the response data. The estimate of the variance-covariance matrix is then incorporated into tests of hypotheses and the construction of confidence intervals concerning model parameters. This allows an analysis of repeated measures data without assuming a specific structure of the variance-covariance matrix. Differences among treatment groups with respect to the corresponding variance-covariance matrices are accounted for by employing Welch's adjustment to the degrees of freedom.

This methodology then was extended to the nonlinear case, employing the well-known asymptotic theory of nonlinear models. In the nonlinear case, by-subject analyses of data are not always possible because of the 
difficulty of iterative techniques to fit a common response model to data from each of several subjects. Often, for complex nonlinear mechanisms, an individual subject's data may not be a good representation of the overall average trend of the group's response. In these cases, the solution with the by-subject analysis could be as drastic as deleting that subject's data from the analysis. In the means approach, it is recognized that each subject's data contributes to the mean response of the group. In addition, using the means approach requires only one application of a nonlinear estimation procedure, which would save substantial computer time. Again, since a model-free estimate of the variance-covariance matrix is computed, testing of hypotheses and construction of confidence intervals is not dependent on an assumed structure of the variance-covariance matrix.

Acknowledgement

Contribution No. 90-47-A, from the Kansas Agricultural Experiment Station, Manhattan, Kansas.

References

1. Draper, N.R. and Smith, H., 1981. Applied Regression Analysis. John Wiley and Sons, New York.

2. Graybill, F.A., 1976. Theory and Application of the Linear Model. Duxbury Press, North Scituate, Massachusetts.

3. Hinds and Milliken, G.A., 1987. Statistical Methods to Use Nonlinear Models to Compare Silage Treatments. Biometrical Journal, 29, 7, $825-834$.

4. Jennrich, R.I., 1969. Asymptotic Properties of Non-Linear Least Squares Estimators. The Annals of Mathematical Statistics, 40, 2, 633-643.

5. Morrison, D.F., 1976. Multivariate Statistical Methods. McGraw-Hill Book Company, New York.

6. Schwenke, J.R. and Milliken, G.A. On the Calibration Problem Extended to Nonlinear Kodels. Submitted to Biometrics.

7. Timm, N.H., 1975. Multivariate Analysis with Applications in Education and Psychology. Brooks/Cole Publishing Company, Monterey, California.

8. Winer, B.J., 1971. Statistical Principles in Experimental Design. McGraw-Hill Book Company, New York. 
Table 1

Observed Across-Subject pH Means by Treatment and Sampling Time

\begin{tabular}{|c|c|c|c|}
\hline \multirow{7}{*}{$\frac{\text { Treatment }}{\text { Control }}$} & $\mathrm{n}$ & Time & Mean ph \\
\hline & 43 & 1 & 6.67 \\
\hline & & 2 & 6.34 \\
\hline & & 4 & 6.02 \\
\hline & & 6 & 5.73 \\
\hline & & 8 & 5.58 \\
\hline & & 24 & 5.45 \\
\hline \multirow[t]{6}{*}{ ES } & 43 & 1 & 6.66 \\
\hline & & 2 & 6.16 \\
\hline & & 4 & 5.71 \\
\hline & & 6 & 5.53 \\
\hline & & 8 & 5.47 \\
\hline & & 24 & \\
\hline
\end{tabular}

Table 2

Sample Variance-Covariance Matrix of Across-Subject phi Means Control (x 10e-3):

$\left[\begin{array}{llllll}1.55 & 1.24 & 1.35 & 0.83 & 0.41 & 0.25 \\ 1.24 & 1.35 & 1.30 & 0.95 & 0.55 & 0.34 \\ 1.35 & 1.30 & 1.89 & 1.10 & 0.65 & 0.35 \\ 0.83 & 0.95 & 1.10 & 1.54 & 0.90 & 0.38 \\ 0.41 & 0.55 & 0.65 & 0.90 & 0.93 & 0.39 \\ 0.25 & 0.34 & 0.35 & 0.38 & 0.40 & 0.48\end{array}\right]$

ES $\left(\begin{array}{ll}x & 10 e-3):\end{array}\right.$

$\left[\begin{array}{rrrrrr}1.36 & 0.71 & 0.18 & 0.01 & -0.06 & 0.11 \\ 0.71 & 0.85 & 0.43 & 0.22 & 0.10 & 0.12 \\ 0.18 & 0.43 & 0.77 & 0.30 & 0.21 & 0.10 \\ 0.01 & 0.22 & 0.30 & 0.45 & 0.26 & 0.04 \\ -0.06 & 0.10 & 0.21 & 0.26 & 0.31 & 0.02 \\ 0.11 & 0.12 & 0.10 & 0.04 & 0.02 & 0.15\end{array}\right]$

Table 3

Estimated Nonlinear Decay Model Parameters $p H=\beta_{0}-\beta_{1}\left(1-\exp \left(-\beta_{2}\right.\right.$ time $\left.)\right)$

\begin{tabular}{cccccc} 
Treatment & $\begin{array}{c}\text { Model } \\
\text { Parameter }\end{array}$ & Estimate & \multicolumn{2}{c}{$\begin{array}{c}95 \% \\
\text { Lower }\end{array}$} & Upper \\
\cline { 2 - 5 } Control & $\beta_{0}$ & 7.054 & 6.955 & 7.153 \\
& $\beta_{1}$ & 1.618 & 1.513 & 1.724 \\
& $\beta_{2}$ & 0.278 & 0.246 & 0.310 \\
\multirow{2}{*}{ ES } & $\beta_{0}$ & 7.447 & 7.263 & 7.630 \\
& $\beta_{1}$ & 2.022 & 1.836 & 2.207 \\
& $\beta_{2}$ & 0.497 & 0.443 & 0.551
\end{tabular}

Sample Correlation Matrix of Estimated Model Parameter Control:

$$
\left[\begin{array}{lll}
1.000 & 0.903 & 0.183 \\
0.903 & 1.000 & 0.130 \\
0.183 & 0.130 & 1.000
\end{array}\right]
$$

ES :

$\left[\begin{array}{lll}1.000 & 0.993 & 0.751 \\ 0.993 & 1.000 & 0.739 \\ 0.751 & 0.739 & 1.000\end{array}\right]$

Table 4

Comparison of model Parameters Control versus ES Treatment

\begin{tabular}{|c|c|c|}
\hline \multicolumn{3}{|c|}{ Model } \\
\hline Parameter & T-Statistic & P-value \\
\hline$\beta_{0}$ & -3.803 & 0.00032 \\
\hline$\hat{\theta}_{1}$ & -3.816 & 0.00030 \\
\hline$B_{0}-A_{1}$ & 0.402 & 0.68886 \\
\hline$\theta_{2}$ & -7.031 & $<0.0001$ \\
\hline
\end{tabular}


Table 5

Estimated Time to Achieve pH 6.0 with Asymptotic 95 Confidence Interval $95 \%$ C. I.

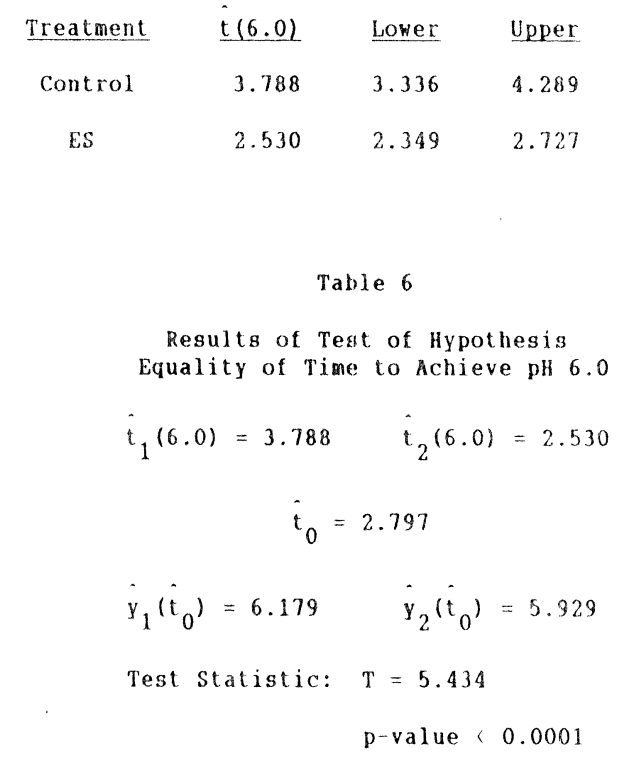

New Prairie Press

https://newprairiepress.org/agstatconference/1989/proceedings/3

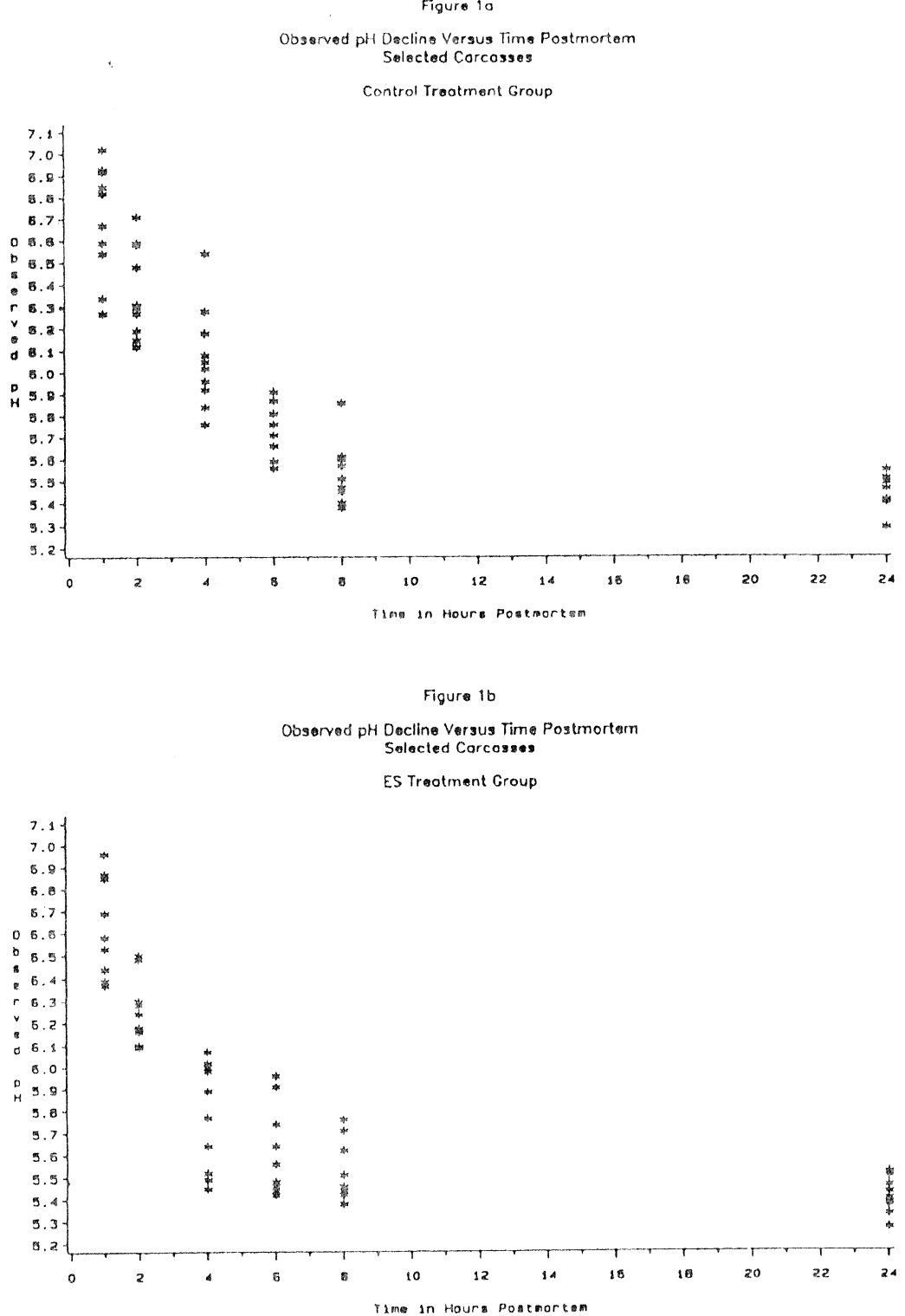


Figure 20

Observed pH Decline Versus Tirne Postmortem Solectod Corca

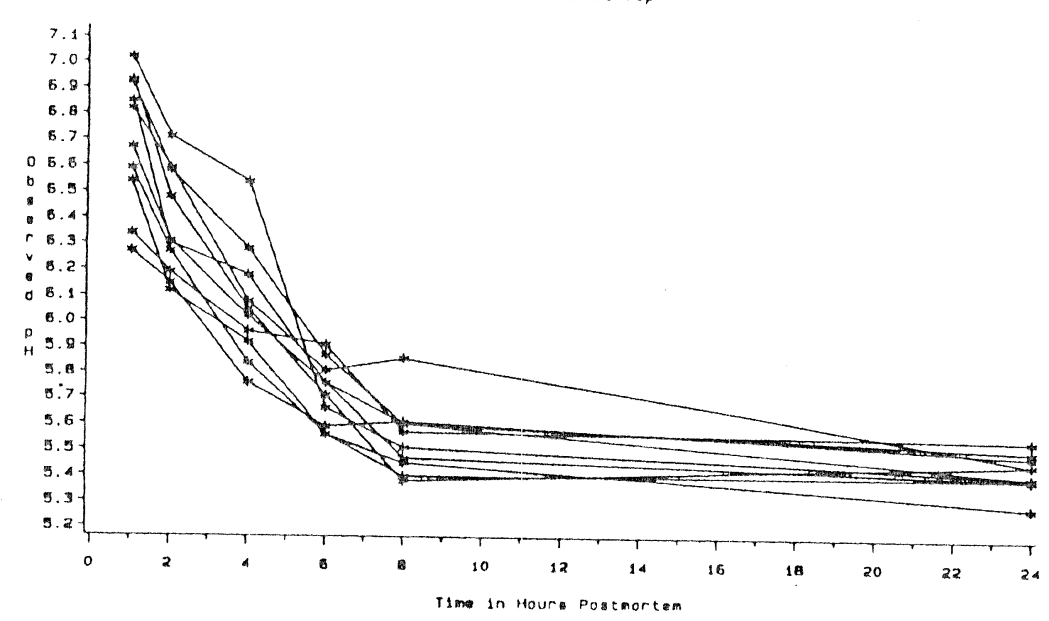

Flgure 20

Obsarved pH Docline Vorsus Rime Postmortern
Selected Corcosses By Corcoss

ES Treotmant Group

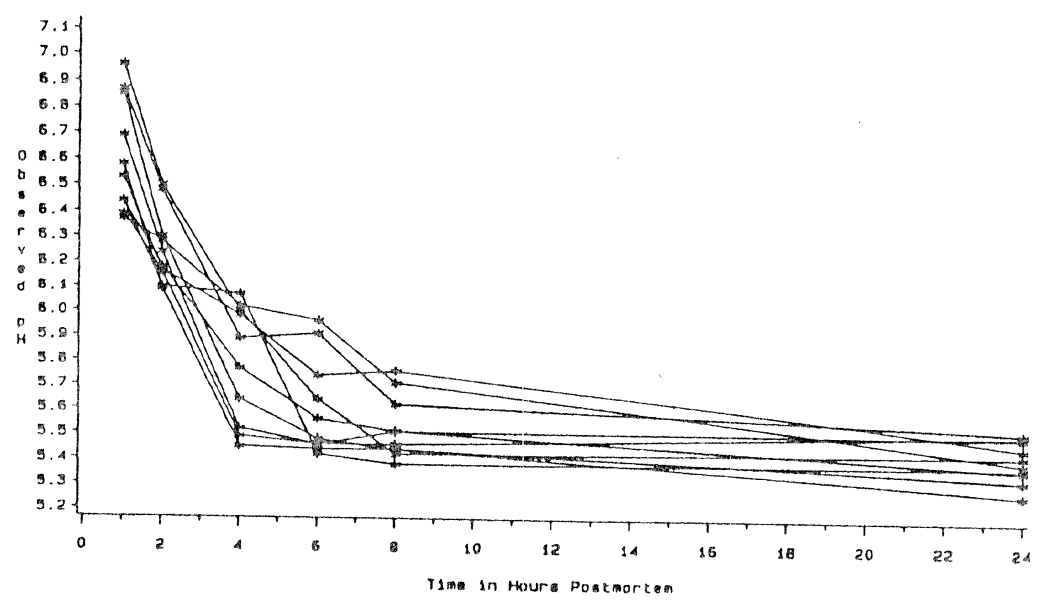

Figure 3o

Observed pH Decline Versus Tims Postmortern

Control Treotment Group

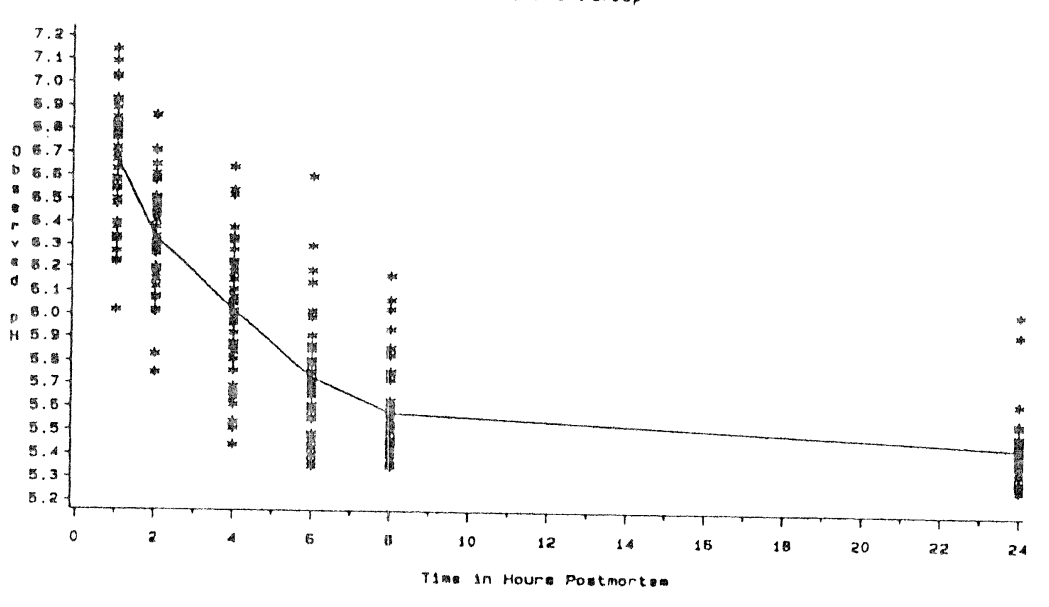

Legeno:

$$
\begin{aligned}
& \text { Figure } 3 b \\
& \text { Observed pH Decline Versug Tims Postmortam } \\
& \text { ond Obsarved Meon Response }
\end{aligned}
$$

ES Treotment Group

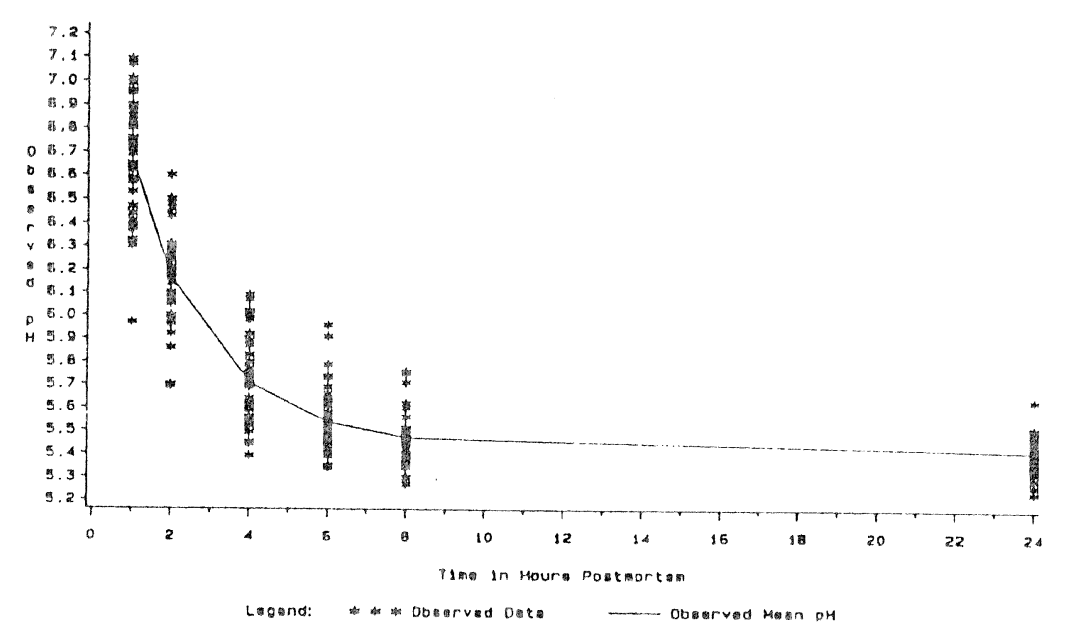


Figure 40

Observiod Moan pH Decllin Versus Tima Postmortem Controtiod Moon Rh

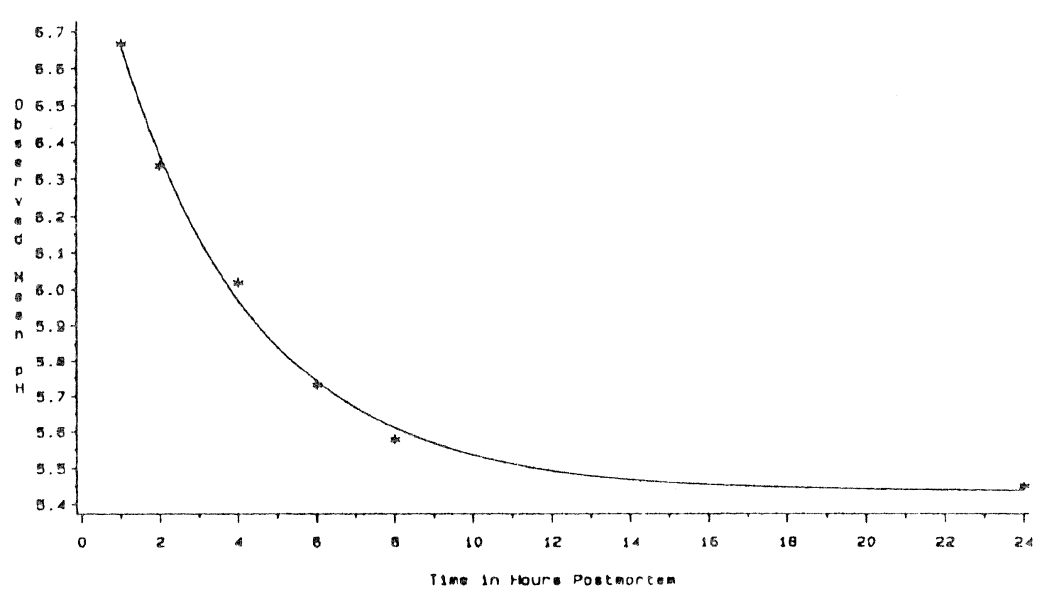

Legend: * * Obeervad Mesen DH EH Eat. Magen Rego

Figure 4b

Observed Maon pH Oecline Versus time Postmortem

ond Estimoled Meon Responses

ES Treotnent Group

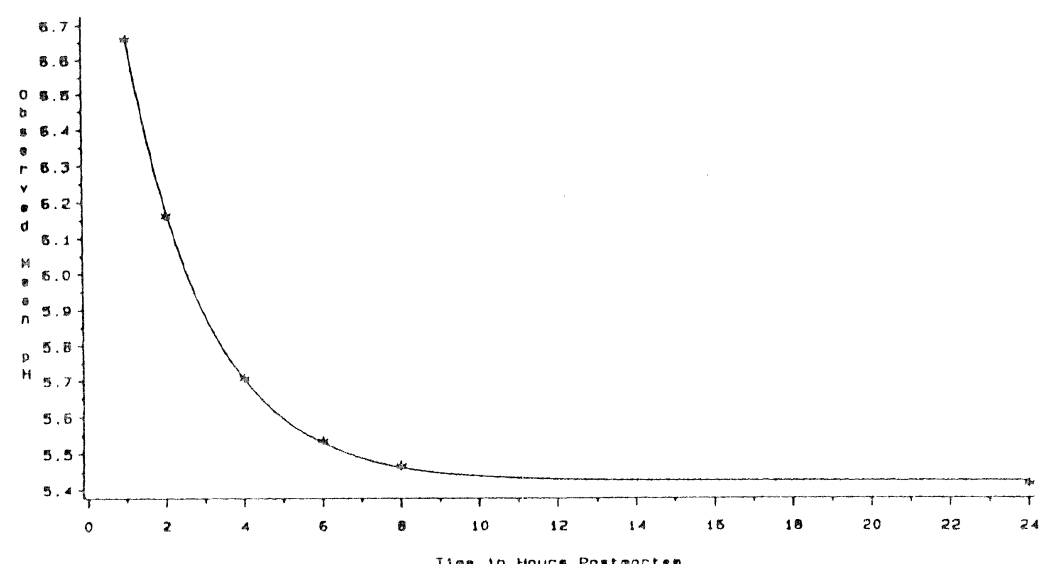

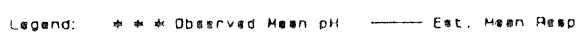

Figure 5

Estimaled Control and ES Maan pH Declines Versus Time Postmortern

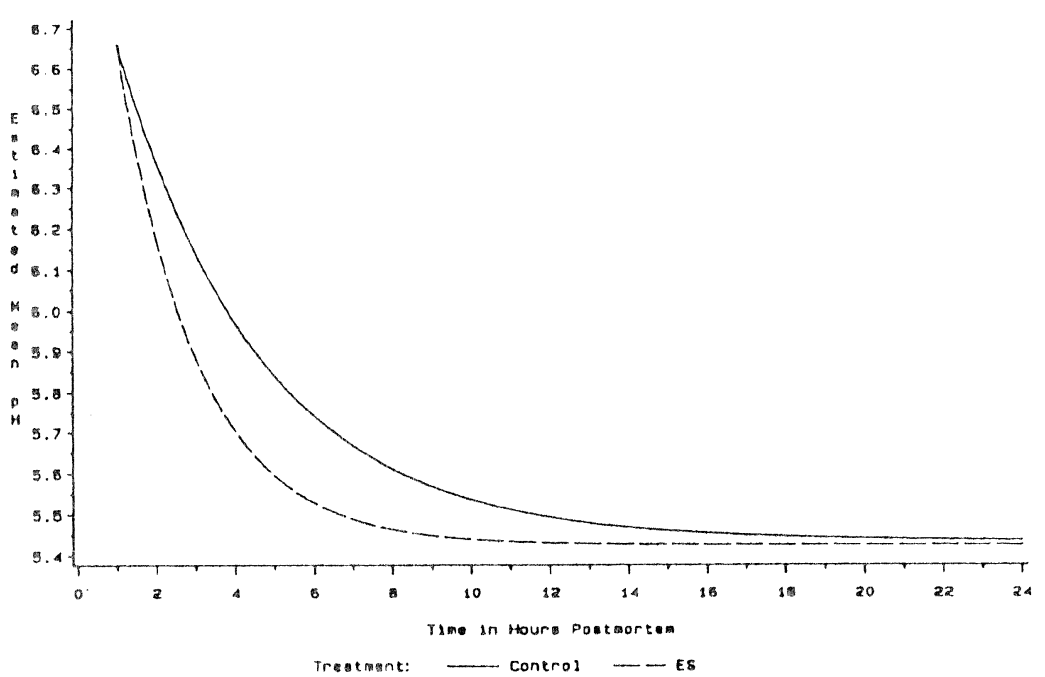

Figura 6

Estimoted Mean Trootmont Difference of Control and ES

(No Significant Difference of 13.91 Hours)

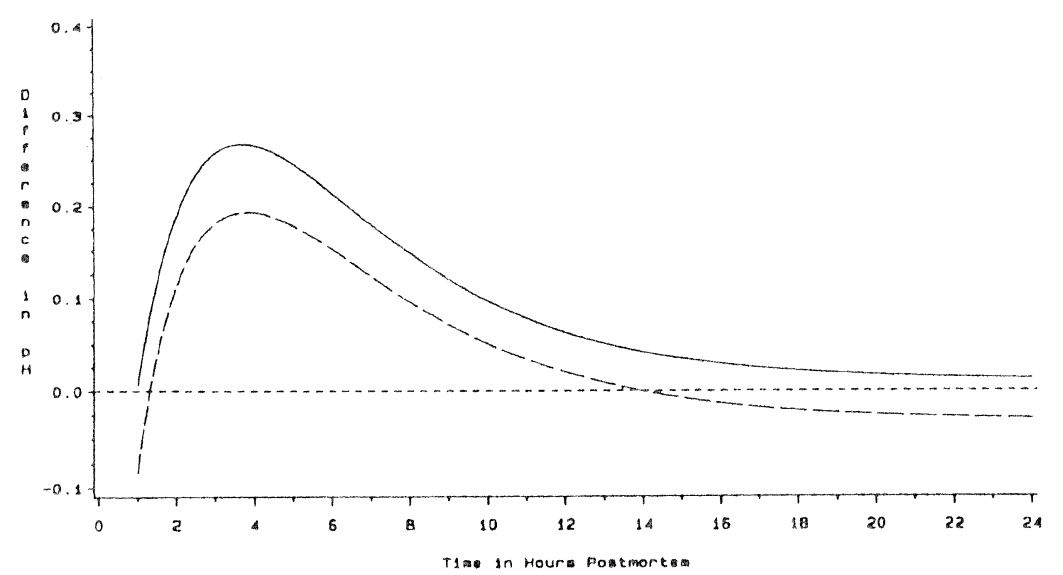

Legend: - Masn Difference - $-95 x$ conp. Bound 